\title{
A Fuzzy Decision-Making Trial and Evaluation Laboratory approach to analyse risk factors related to environmental health and safety aspects in the healthcare industry
}

\author{
R K A BHALAJI $^{1}{ }^{\oplus}$, S BATHRINATH $^{1, *}, \mathrm{~S} \mathrm{G} \mathrm{PONNAMBALAM}^{2}$ and S SARAVANASANKAR ${ }^{1}$ \\ ${ }^{1}$ Department of Mechanical Engineering, Kalasalingam Academy of Research and Education, \\ Krishnankoil 626126, India \\ ${ }^{2}$ Faculty of Manufacturing Engineering, Universiti Malaysia, 26600 Pekan, Pahang, Malaysia \\ e-mail: bathri@gmail.com
}

MS received 13 August 2018; revised 29 November 2018; accepted 29 November 2018; published online 9 February 2019

\begin{abstract}
In healthcare firms, environmental health and safety (EHS) remains as a vital factor as healthcare products pose very intricate problems related to environment safety. The different similar and dissimilar risk factors that prevail in the system have complicated known and unknown causal relationships that are difficult to understand and interpret. Hence, improving the EHS remains as a challenge in healthcare industry. A research study is carried out utilizing the data (in conjunction with expert's opinion) and conditions of a healthcare firm in India to categorize and obtain the prominent risk factors based on identifying the most adverse causal relationship among them. A Fuzzy Decision-Making Trial and Evaluation Laboratory (fuzzy DEMATEL)-based approach is designed and employed to assess and rank different EHS risk factors. The trapezoidal fuzzy membership function of the model facilitates better learning of interrelationships in spite of the prevailing vagueness in the causal relationships between the risk factors. The outcomes (the decisive risk factors) out of the experimentation using the proposed methodology strongly coincide with the actual causes of the EHS factors during the last one decade. As the proposed approach is found to be very effective in fixing the causal relationships and ranking among the risk factors, this may be successfully employed in similar healthcare firms/ industries for finding out their respective decisive risk factors.
\end{abstract}

Keywords. Fuzzy DEMATEL; EHS; healthcare; risk factors; India.

\section{Introduction}

The healthcare industry is highly regulated and are managed by federal, state and local regulatory agencies with the obligation of creating and maintaining a safe, healthy and sustainable condition for patients and employees. It is also required for the development of a nation, and has to combat effluents, pollutants and wastes generated. Hence, the healthcare industry needs to maintain environmental health and safety (EHS) [1]. It has become an industry norm and statutory requirement for the healthcare industry to adhere to the laws and guidelines relating to EHS laid down by the relevant regulatory bodies. More than anything else, EHS is necessary to guarantee the safety and consent to Good Manufacturing Practices (GMP). Alongside secure and more beneficial employees, a solid EHS management system (EMS) can work wonders in expanding the efficiency of an organization. Diseases related to healthcare industry influence between $5 \%$ and $30 \%$ of patients and staff. The

*For correspondence related weight of sickness is high, and heavily depletes healthcare sector assets and families. Implementing safe ecological wellbeing conditions in healthcare can decrease transmission of healthcare-related diseases. EHS interventions in healthcare facilities act to lessen the disease, as they are focused on high-risk populations. These interventions provide a chance to advance safe environments that are significant to populations everywhere. They also contribute to safe environments at home. EHS guidelines should be strictly followed by health and safety managers, clinical and nursing staff, water and sanitation staff and other healthcare suppliers and healthcare promoters. Further, EHS in healthcare industries is studied by numerous specialists [2-4].

\section{Relevant literature}

The review of EHS literature is classified into three sections: (i) risk factors involved in EHS of healthcare industries, (ii) risk factors involved in EHS of other industries and (iii) usage of soft computing tools to analyse risk factors in EHS. 


\subsection{Risk factors involved in EHS of the healthcare industry}

Nieva and Sorra [5] presented wellbeing culture appraisal, a device for enhancing patient wellbeing in healthcare administration. It shows that wellbeing culture appraisal includes dedication of staff time and assets. It can be utilized to quantify administrative conditions that prompt harmful occasions and patient damage, and for creating and assessing safety mediations in healthcare administrations. Baicker et al [6] stated that work environment wellbeing projects can produce reserve funds. The outcome suggested that employer-based wellbeing programmes and activities may not just enhance wellbeing but result in generous savings, and help budgets and productivity in addition to wellbeing results. Govindarajulu and Daily [7] exhibited a structure for environmental performance by inspiring workers. It was expected that workers associated with environmental endeavours might improve an organization towards superior environmental performance. The result shows that top management ought to help a system by formalizing EMS and conveying the significance of worker inspiration in ecological change, while directors and managers should likewise include workers at all levels in satisfying ecological development objectives. Hignett et al [8] presented a mandate to guard labour against risks when taking care of heavy loads. To exclude this risk, execution of the Union order on manual controlling within the healthcare sector was mooted. It was proposed that mediation should be founded on an organizational wellbeing culture method where patient dealing is fully incorporated into clinical preparation, in view of learning principles and abilities. Duijm et al [9] studied the management of wellbeing and security in the process industry. They used the inputs and guidelines adopted by the industry in their model to recognize patterns and requirements for development. Management activities connected to health, safety and environment (HSE) should be sufficient and organized to enhance HSE quality effectively.

\subsection{Risk factors involved in EHS of other industries}

Phimister et al [10] introduced a systematic structure for the examination and development of close miss programmes in chemical process industries that enhance corporate ecological, wellbeing and security execution through the recognizing and administration of close misses. Shen and Tam [11] studied the execution of environmental boards in the construction industry that has an immediate commitment to environmental assurance and includes assigning assets for practicing different environmental management strategies, for example noise control, treatment of contaminated water, waste recycling and reuse, etc. It was observed that decrease of environmental risk, enhancing environmental image and cost reduction due to lessening of environment-related convictions were the most critical advantages of executing environmental management in the construction industry. It should assist temporary workers to change their environmental management approach through effective resources inside their companies. Lee et al [12] proposed the environmental wellbeing and security considerations of nanomaterials in the construction industry. To accomplish environmentally capable nanotechnology in construction, it is essential to consider the lifecycle effects of MNM on the wellbeing of construction employees and inhabitants, and in addition unintended ecological impact during assembling, construction, utilization, annihilation and removal.

\subsection{Usage of soft computing tools to analyse risk factors in EHS}

Ilangkumaran et al [13] examined risk investigation and the cautioning rate for hot conditions in the foundry industry using multicriteria decision making (MCDM) methods. A man working in a hot condition has a serious risk of heatrelated wellbeing issues. Consequently, these devices support the evaluators and chiefs in industry to investigate and survey the risk and guarantee safe working conditions. Reyes et al [14] presented health and safety criteria for choosing reasonable construction schemes using MCDM techniques. The health and safety record for financial assessment of two projects were observed by them. They found that the health and safety for scheme A was greater than for scheme B, implying increased sustainability. Finally, they concluded that if sustainability problems were given more attention in construction industry, better buildings with more secure, affordable and environmental friendliness could be raised. Hatami-Marbini et al [15] proposed a protection and wellbeing evaluation in dangerous litter reusing facilities through MCDM methods. Litter is a potential risk to human wellbeing as the environment turns more destructive, harmful and irresistible. Subsequently, there is a need for an ecological administration framework that aims at decreasing and arranging litter in an environmentally healthy way that secures human and ecological wellbeing to help decision makers shape their thoughts and sort out decisions; it should be utilized very carefully. Jozi et al [16] studied the ecological risk appraisal of dams in the construction industry using MCDM methods. The result suggested that cut and fill, blast, falling from heights and boring are the maximum vital ecological risks in the construction phase. In other words, risk assessment will secure the dam's construction and working staff against risk and also save nearby villagers from possible danger. Zheng et al [17] analysed work safety in hot and damp situations using an MCDM method like analytical hierarchy process (AHP). They showed that the comprehensive security file, wellbeing 
grade and early cautioning rate can be resolved. The outcomes exhibit engineering practicability and the efficiency of the strategies adopted in extreme environmental assessment. Gupta and Thakkar [18] proposed a risk measurement approach and showed its application for a developed construction venture. This work embraces an incorporated way to order risks using MCDM methods like GTOPSIS and to measure risks in terms of general task postpones using JRAP and MCS. They concluded that risks are extremely reliant on task plan and the suggested approach could provide a superior risk order list for the reason that it considers slackness related with the venture activities. Rajak et al [19] examined the interdependences among sustainability criteria and chose the finest sustainable provider in the fuzzy environment using the AHP, TOPSIS and fuzzy inference system and a MATLAB toolbox.

\section{Risk factors affecting EHS in healthcare industry}

The healthcare industry is one of the world's biggest and quickest-developing industries. In this research, a renowned healthcare firm in India was chosen for investigating risk factors that affect EHS in the firm. There are certain risk factors that need to be identified and analysed correctly to ensure effective EHS in healthcare industries. Factors affecting EHS in healthcare industries can be identified through a literature review. As per literature, there is no research on finding risk factors affecting EHS in healthcare industries. The risks factors affecting EHS in healthcare industry are collected from the literature and are presented in table 1.

\section{Methodology}

A Fuzzy Decision-Making Trial and Evaluation Laboratory (fuzzy DEMATEL) is proposed to solve the problem. The key factors related to EHS healthcare industries identified

Table 1. Categories of risk.

\begin{tabular}{lccc}
\hline S1. no. & Risk factors & Notation & References \\
\hline 1 & Process risk & F1 & {$[20,21]$} \\
2 & Factory age & F2 & {$[22,23]$} \\
3 & Raw materials & F3 & {$[24,25]$} \\
4 & Engineering-based risk & F4 & {$[26,27]$} \\
5 & Psychological & F5 & {$[28,29]$} \\
6 & Cultural & F6 & {$[5,30]$} \\
7 & Hygienic programme & F7 & {$[6,31]$} \\
8 & Government norms & F8 & {$[32,33]$} \\
9 & Employee awareness & F9 & {$[7,34]$} \\
10 & Stakeholders & F10 & {$[35,36]$} \\
11 & Emergencies & F11 & {$[37,38]$} \\
12 & Union & F12 & {$[8,39]$} \\
\hline
\end{tabular}

are based on the survey from existing literature as well as inputs from experts in this field and they are examined using the fuzzy DEMATEL. Fuzzy DEMATEL tool aids in finding the consequences of causal relations among factors.

\subsection{Fuzzy set theory}

The information obtained through the fuzzy set theory might be probabilistic or uncertain and even vague in general. Zadeh [40] proposed the superiority of fuzzy sets in decision making under the status of insufficient information data. Human needs were not required to solve fuzzy set theory once it was assigned by linguistic values to solve complicated problems. Considering real life scenario, decision makers' judgments were defined as expressions that when given to linguistic constants were given in terms of fuzzy notations. Based on the literature survey, it is found that triangular and trapezoidal fuzzy membership functions were used most frequently by the researchers and practitioners. A trapezoidal membership function is used in this research, where $X 1$ denotes a set of objects, $A 1$ is the fuzzy set for the set of objects and $x 1$ is the element in $X 1$. Then, $\mu_{A 1}(X 1)$ denotes its membership function. In this research, a specialized fuzzy number called trapezoidal fuzzy number (TrapFN) is used.

Let $A 1=(a 1, b 1, c 1, d 1)$ be a trapezoidal membership function that is mathematically expressed using Eq. (1), where $a 1 \leq b 1 \leq c 1 \leq d 1$; for any two TrapFN, $A 1=$ $(a 1, b 1, c 1, d 1)$ and $A 2=(p 1, q 1, r 1, s 1)$ will be equal if and only if $a 1=p 1, b 1=q 1, c 1=r 1, d 1=s 1$ :

$$
\mu_{A 1}(X 1)=\left[\begin{array}{cc}
0, & x 1<a 1 \\
\frac{x 1-a 1}{x 1-b 1}, & a 1 \leq x 1 \leq b 1 \\
1, & b 1 \leq x 1 \leq c 1 \\
\frac{d 1-x 1}{d 1-c 1}, & c 1 \leq x 1 \leq d 1 \\
0, & x 1>d 1 .
\end{array}\right]
$$

\subsection{Fuzzy DEMATEL}

DEMATEL is a methodology that uses causal and effect diagrams helpful to understand basic interactions among key factors in EHS aspects in healthcare industries. Even so, DEMATEL is not likely to manage human predictions and data vagueness. To avoid such consequences, fuzzy DEMATEL is proposed in this work. Data fuzziness was managed by fuzzy logic, which coverts data to crisp values [41]. The combined merits of DEMATEL and fuzzy logic are exploited by formulating a fuzzy DEMATEL model to examine and apportion the recognized key factors of EHS in healthcare industries. The formulated fuzzy DEMATEL not only figures out the uncertainty in examining causal relations among factors but also speculates a plan of action to manage EHS. Some fuzzy DEMATEL applications found in the literature are presented in table 2. 
Table 2. Applications of fuzzy DEMATEL.

\begin{tabular}{lcc}
\hline $\begin{array}{l}\text { S1. } \\
\text { no. }\end{array}$ & Application area & References \\
\hline 1 & Facility layout problem in the machinery & {$[42]$} \\
& industry \\
2 & Knowledge management adoption in the & {$[43]$} \\
& supply chain of a hydraulic valve \\
& manufacturing organization \\
3 & Inowits software organization & {$[44]$} \\
4 & Mining industry & {$[45]$} \\
5 & Supplier selection & {$[46]$} \\
6 & Crisis management & {$[47]$} \\
7 & Truck selection of land transportation & {$[48]$} \\
8 & company & {$[49]$} \\
9 & Municipal solid waste management in Metro & {$[50]$} \\
& Manila & {$[51]$} \\
10 & Logistics idea assortment in Belgrade & \\
\hline
\end{tabular}

The steps of the fuzzy DEMATEL adopted from [52] and [41] are presented here.

Step 1: Seeking expert's opinions and categorizing evaluation criteria.

A panel of experts is established and valuable suggestions on related subjects are obtained. The key factors of EHS in the healthcare industry were identified from existing literature and from the panel of subject experts established.

\section{Step 2: Obtaining a Fuzzy Direct Assessment Matrix (FDAM).}

Once the assessment criteria are completed, pairwise comparison for criteria is essential. For this, a fuzzy linguistic scale with five different points $(0=$ no influence, $1=$ very low influence, $2=$ low influence, 3 =high influence, $4=$ very high influence) is used to aid decision makers to evaluate the interrelation among various criteria. Decision makers are requested to assign rating based on the fuzzy linguistic scale for the development of an assessment matrix as part of the evaluation criteria. When assessing and modifying linguistic content from decision makers, predictions go into fuzzy evaluations, leading to an optimistic TrapFN presented in table 3 . TrapFN is represented by a quadruplet, i.e., $\left(a 1_{i j}, b 1_{i j}, c 1_{i j}, d 1_{i j}\right)$, where $a 1 \leq b 1 \leq$ $c 1 \leq d 1$. Let $x 1_{i j}^{k}=\left(a 1_{i j}^{k}, b 1_{i j}^{k}, c 1_{i j}^{k}, d 1_{i j}^{k}\right)$, where $1 \leq k \leq k$, be the fuzzy classification that the $k$ th decision maker provides for rating if factor $i$ affects factorj.

Step 3: Obtain a Fuzzy Initial Direct Relation Matrix (FIDRM).

Defuzzification is the process of changing fuzzy numbers to corresponding crisp values. FIDRM is obtained due to the separation of the region (technique), when defuzzification of
Table 3. Fuzzy linguistic scale used in this research.

\begin{tabular}{lcc}
\hline $\begin{array}{l}\text { Five-point score for } \\
\text { decision makers } \\
\text { preference }\end{array}$ & $\begin{array}{c}\text { Linguistic } \\
\text { constants and } \\
\text { their description }\end{array}$ & $\begin{array}{c}\text { Trapezoidal fuzzy } \\
\text { numbers (TrapFN) for } \\
\text { equivalent scores }\end{array}$ \\
\hline 0 & $\begin{array}{c}\text { No influence } \\
\text { (No) } \\
\text { Very low } \\
\text { influence (VL) }\end{array}$ & $(0,0,0.1,0.2)$ \\
2 & $\begin{array}{c}\text { Low influence } \\
\text { (L) }\end{array}$ & $(0.1,0.2,0.3,0.4)$ \\
3 & $\begin{array}{c}\text { High influence } \\
\text { (H) } \\
\text { Very high } \\
\text { influence } \\
(\mathrm{VH})\end{array}$ & $(0.5,0.6,0.7,0.8)$ \\
& $(0.7,0.8,0.9,1)$ \\
\hline
\end{tabular}

fuzzy assessment matrix is undertaken utilizing Eq. (2). Average $k$ obtained from $n \times n$ FIDRM is computed for all decision makers, where $k$ is the number of decision makers:

$$
I_{T}=\frac{1}{4}(a 1+b 1+c 1+d 1) .
$$

Step 4: Obtain the normalized, initial, direct relation matrix (NIRDM) using Eqs. (3) and (4):

$$
m=\min \left[\frac{1}{\max \sum_{j=1}^{n}\left|a_{i j}\right|}, \frac{1}{\max \sum_{i=1}^{n}\left|a_{i j}\right|}\right],
$$

Step 5: Construct the Total Relation Matrix (TRM) using Eq. (5) as follows:

$$
T R M=(I-N I D R M)^{-1}
$$

where $I=$ identity matrix and $T R M=\left[t_{i j}\right]_{n \times n}$.

Step 6: Calculate the summation of rows $\left(\operatorname{Row}_{i}\right)$ and the summation of columns $\left(\mathrm{Col}_{i}\right)$ utilizing Eqs. (6) and (7) as follows:

$$
\operatorname{Row}_{i}=\left\{\sum_{j=1}^{n} t_{i j}\right\}_{n \times 1},
$$

$$
\operatorname{Col}_{i}=\left\{\sum_{i=1}^{n} t_{i j}\right\}_{1 \times n} .
$$




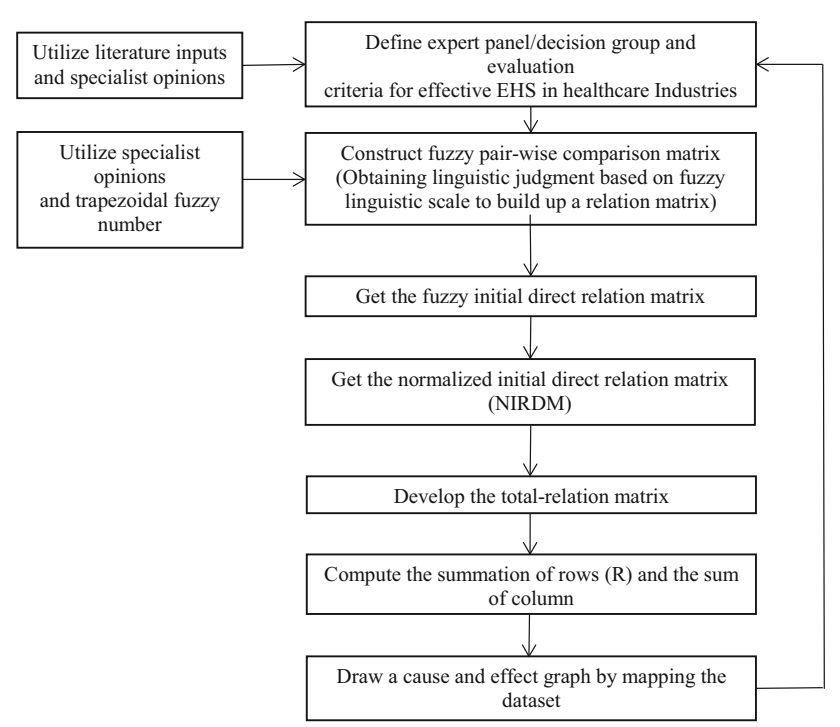

Figure 1. Fuzzy DEMATEL flow chart.

Row $_{i}$ denotes the general impact of one criterion, say impact of criterion $i$ on criterion $j$, and $\mathrm{Col}_{i}$ denotes the general impact experienced by criterion $j$ because of criterion $i$.

Step 7: Draw a cause and effect graph (CEG) by processing the data set of

$$
\left(\text { Row }_{i}+\operatorname{col}_{i} ; \text { Row }_{i}-\text { Col }_{i}\right)
$$

The data set $\left(\right.$ Row $\left._{i}+\mathrm{Col}_{i}\right)$ shows the significance of key criteria and its 'Prominence' in EHS of healthcare industries, while $\left(\right.$ Row $\left._{i}-\mathrm{Col}_{i}\right)$ shows the impact of similar factors 'Influence'. If a positive value is obtained from $\left(\right.$ Row $\left._{i}-\mathrm{Col}_{i}\right)$, then the factor falls under the cause group, and if $\left(\operatorname{Row}_{i}-\mathrm{Col}_{i}\right)$ value is pessimistic, the factor falls under the effect group. A flowchart of steps regarding the process associated with fuzzy DEMATEL method is shown in figure 1.

\section{Empirical case study}

The factors of EHS in a healthcare firm in India were analysed by the suggested decision-making methodology. As per the reports obtained from the industries for the past 10 years, employees face environment-related issues almost every month throughout the year. It is also comprehended that works get delayed due to the risks engaged in this firm. The firm considered for this study is one of the leading private healthcare industry in India; the annual turnover of the firm is more than 60 crores of Indian Rupees and it is also known for its reputation. Over 400 direct and 150 indirect employees are involved in routine activities of the firm. For successful implementation of EHS activities, it is important to analyse the risk factors related to EHS. The consequence of this research will surely aid the EHS managers to comprehend the different risks involved in the firm by implementing EMS for minimizing its severity. To exemplify the suggested methodology there are three stages that need to be followed, which are discussed here.

Stage Data gathering and identification of key factors of 1: $\quad$ EHS.

The key factors are gathered from the literature review, straight interviews and inputs from industrial experts. For this issue, primarily we approached a team of decision makers including two managers in the senior cadre from healthcare industry who practice EHS, a senior academician from the institution of health and safety, and a member from the Ministry of Environment under the Government of India is formed to characterize and to determine key factors of EHS in healthcare industries. The chosen decision makers are knowledgeable in their relevant areas and are skilled in decision making. The choice of decision makers is based on the source of working knowledge (at least ten years' experience) and expertise in their domains. Twelve key factors of EHS in healthcare industries chosen based on the literature review match with the decision maker's views. The questionnaire is given in Appendix A to obtain decision makers opinion.

Table 4. Fuzzy initial direct relation matrix.

\begin{tabular}{|c|c|c|c|c|c|c|c|c|c|c|c|c|}
\hline & $\mathrm{F} 1$ & $\mathrm{~F} 2$ & F3 & $\mathrm{F} 4$ & F5 & F6 & F7 & F8 & F9 & F10 & F11 & F12 \\
\hline 1. Process risk $(\mathrm{F} 1)$ & 0 & 4 & 4 & 4 & 0 & 0 & 3 & 4 & 2 & 3 & 4 & 0 \\
\hline 2. Factory age (F2) & 3 & 0 & 0 & 3 & 2 & 1 & 2 & 0 & 2 & 0 & 2 & 3 \\
\hline 3. Raw materials (F3) & 4 & 0 & 0 & 2 & 0 & 0 & 4 & 4 & 0 & 2 & 4 & 0 \\
\hline 4. Engineering-based risk $(\mathrm{F} 4)$ & 4 & 0 & 0 & 0 & 0 & 0 & 4 & 4 & 3 & 0 & 3 & 0 \\
\hline 5. Psychological (F5) & 2 & 0 & 0 & 0 & 0 & 4 & 2 & 2 & 4 & 2 & 2 & 4 \\
\hline 6. Cultural (F6) & 1 & 0 & 0 & 0 & 4 & 0 & 2 & 2 & 4 & 3 & 1 & 4 \\
\hline 7. Hygienic programme (F7) & 4 & 0 & 4 & 4 & 2 & 2 & 0 & 4 & 2 & 0 & 0 & 1 \\
\hline 8. Government norms (F8) & 3 & 0 & 3 & 4 & 0 & 0 & 4 & 0 & 4 & 4 & 4 & 3 \\
\hline 9. Employee awareness (F9) & 3 & 0 & 0 & 2 & 3 & 4 & 3 & 1 & 0 & 0 & 2 & 4 \\
\hline 10. Stakeholders (F10) & 0 & 0 & 0 & 0 & 0 & 2 & 0 & 3 & 0 & 0 & 3 & 0 \\
\hline 11. Emergencies (F11) & 3 & 0 & 4 & 4 & 0 & 0 & 2 & 4 & 2 & 4 & 0 & 0 \\
\hline 12. Union (F12) & 0 & 2 & 0 & 0 & 4 & 4 & 0 & 3 & 4 & 0 & 0 & 0 \\
\hline
\end{tabular}




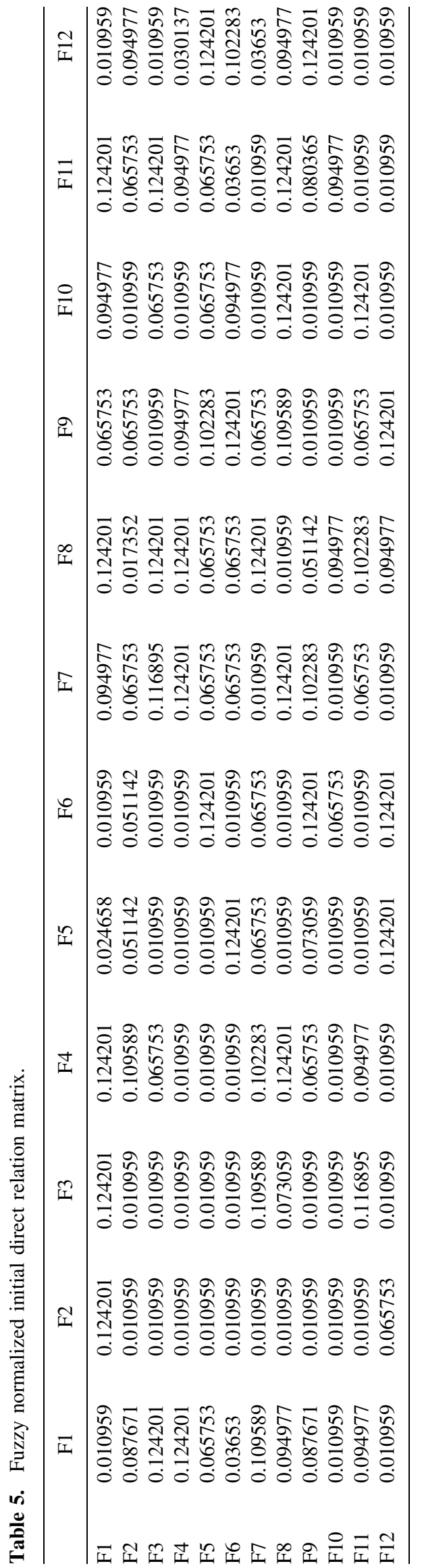

Stage 2: Analysing the factors of EHS using fuzzy DEMATEL.

The next stage is to examine the key factors of EHS recognized from stage 1 . The factors of EHS will be examined through fuzzy DEMATEL. The step by step analysis of factors with fuzzy DEMATEL is given as follows.

Step 1: Pairwise comparison by decision makers among key factors of EHS in healthcare industries utilizing a point scale is shown in table 3. The fuzzy assessment matrix suggested by the four decision makers is presented in Appendix B.

Step 2: To develop initial direct relation matrix or normal matrix, fuzzy numbers are changed to crisp values by defuzzification as recommended in Step 3 of the fuzzy DEMATEL approach. FIDRM of key factors in EHS in the healthcare industry is presented in table 4.

Step 3: NIRDM of factors was accomplished by Eqs. (3) and (4). Fuzzy NIRDM of key factors in EHS in the healthcare industry is given in table 5 .

Step 4: TRM of key factors of EHS in the healthcare industry is obtained using Eq. (5) as shown in table 6.

Step 5: The row-wise sum $\left(\right.$ Row $\left._{i}\right)$ and the column-wise sum $\left(\mathrm{Col}_{i}\right)$ of factors in the EHS in healthcare industry are computed using Eqs. (6) and (7), respectively.

Step 6: Data sets $\left(\operatorname{Row}_{i}+\mathrm{Col}_{i}\right)$ and $\left(\operatorname{Row}_{i}-\mathrm{Col}_{i}\right)$ data sets of key factors of EHS in the healthcare industry are exhibited in table 7.

Also, positioning of EHS key factors in the healthcare industry is done based on $\left(\operatorname{Row}_{i}+\operatorname{Col}_{i}\right)$ data set and the $\left(\right.$ Row $\left._{i}-\mathrm{Col}_{i}\right)$ data. The key factors are classified as a cause or effect group (see table 5). In the last stage, $\left(\right.$ Row $_{i}+$ Col $\left._{i}\right)$ and $\left(\right.$ Row $_{i}-$ Col $\left._{i}\right)$ data sets are created to infer from the causal diagram, which is exhibited in figure 2.

The significance of this factor is known as Prominence $\left(\operatorname{Row}_{i}+\operatorname{Col}_{i}\right)$. The influence $\left(\operatorname{Row}_{i}-\mathrm{Col}_{i}\right)$ categorizes the cause and effect group. The knowledge for EHS analysis in the healthcare industry is provided by the causal effect diagram. Based on the analysis of different factors, their corresponding positions and relative significance in the framework, managers recognize factors influencing EHS choices and helpful for them to make decisions accordingly. Tables 8 and 9 present cause and effect group, respectively.

Stage 3: Result verification.

The third and final stage of this study is to verify final outcomes. The verification is acquired from industrial experts by means of sending final outcomes of this research for clarification as well as by verifying the results with existing literatures. After verification, final outcomes are presented to the healthcare firm. 
Table 6. Fuzzy Total Relation Matrix.

\begin{tabular}{|c|c|c|c|c|c|c|c|c|c|c|c|c|}
\hline & F1 & $\mathrm{F} 2$ & F3 & $\mathrm{F} 4$ & F5 & F6 & F7 & F8 & F9 & F10 & F11 & F12 \\
\hline $\mathrm{F} 1$ & 0.27 & 0.2 & 0.29 & 0.35 & 0.15 & 0.16 & 0.34 & 0.4 & 0.29 & 0.28 & 0.36 & 0.18 \\
\hline $\mathrm{F} 2$ & 0.25 & 0.077 & 0.13 & 0.26 & 0.15 & 0.17 & 0.23 & 0.22 & 0.23 & 0.14 & 0.22 & 0.22 \\
\hline F3 & 0.31 & 0.081 & 0.16 & 0.25 & 0.1 & 0.12 & 0.31 & 0.35 & 0.19 & 0.22 & 0.31 & 0.13 \\
\hline F4 & 0.31 & 0.082 & 0.15 & 0.19 & 0.11 & 0.13 & 0.31 & 0.34 & 0.27 & 0.16 & 0.28 & 0.16 \\
\hline F5 & 0.24 & 0.08 & 0.13 & 0.17 & 0.13 & 0.26 & 0.24 & 0.28 & 0.29 & 0.21 & 0.24 & 0.26 \\
\hline F6 & 0.2 & 0.073 & 0.12 & 0.16 & 0.23 & 0.15 & 0.23 & 0.26 & 0.29 & 0.22 & 0.2 & 0.24 \\
\hline F7 & 0.31 & 0.085 & 0.24 & 0.28 & 0.17 & 0.19 & 0.22 & 0.35 & 0.26 & 0.17 & 0.22 & 0.18 \\
\hline F8 & 0.33 & 0.096 & 0.23 & 0.33 & 0.14 & 0.16 & 0.35 & 0.29 & 0.32 & 0.29 & 0.35 & 0.24 \\
\hline F9 & 0.28 & 0.086 & 0.15 & 0.24 & 0.2 & 0.26 & 0.29 & 0.28 & 0.22 & 0.17 & 0.26 & 0.27 \\
\hline F10 & 0.11 & 0.042 & 0.08 & 0.1 & 0.064 & 0.12 & 0.11 & 0.2 & 0.11 & 0.096 & 0.19 & 0.08 \\
\hline F11 & 0.28 & 0.078 & 0.24 & 0.27 & 0.1 & 0.12 & 0.26 & 0.32 & 0.23 & 0.27 & 0.21 & 0.13 \\
\hline $\mathrm{F} 12$ & 0.17 & 0.12 & 0.1 & 0.15 & 0.23 & 0.25 & 0.17 & 0.26 & 0.29 & 0.14 & 0.16 & 0.15 \\
\hline
\end{tabular}

Table 7. Calculation of $\left(\operatorname{Row}_{i}+\mathrm{Col}_{i}\right)$ and $\left(\operatorname{Row}_{i}-\mathrm{Col}_{i}\right)$ data sets of key factors in EHS.

\begin{tabular}{|c|c|c|c|c|c|c|}
\hline Barriers & Row $_{i}$ & $\mathrm{Col}_{i}$ & $\operatorname{Row}_{i}+\mathrm{Col}_{i}$ & Rank & Row $_{i}-$ Col $_{i}$ & Cause/effect \\
\hline F1 & 3.27 & 3.06 & 6.33 & 2 & 0.21 & Cause \\
\hline $\mathrm{F} 2$ & 2.297 & 1.1 & 3.397 & 12 & 1.197 & Cause \\
\hline F3 & 2.531 & 2.02 & 4.551 & 7 & 0.511 & Cause \\
\hline $\mathrm{F} 4$ & 2.492 & 2.75 & 5.242 & 6 & -0.258 & Effect \\
\hline F5 & 2.53 & 1.774 & 5.508 & 10 & 0.756 & Cause \\
\hline F6 & 2.373 & 2.09 & 4.463 & 8 & 0.283 & Cause \\
\hline F7 & 2.675 & 3.06 & 5.735 & 3 & -0.385 & Effect \\
\hline F8 & 3.126 & 3.55 & 6.676 & 1 & -0.424 & Effect \\
\hline F9 & 2.706 & 2.99 & 5.696 & 4 & -0.284 & Effect \\
\hline F10 & 1.302 & 2.366 & 3.668 & 11 & -1.064 & Effect \\
\hline F11 & 2.508 & 3 & 5.508 & 5 & -0.492 & Effect \\
\hline F12 & 2.19 & 2.24 & 4.43 & 9 & -0.05 & Effect \\
\hline
\end{tabular}

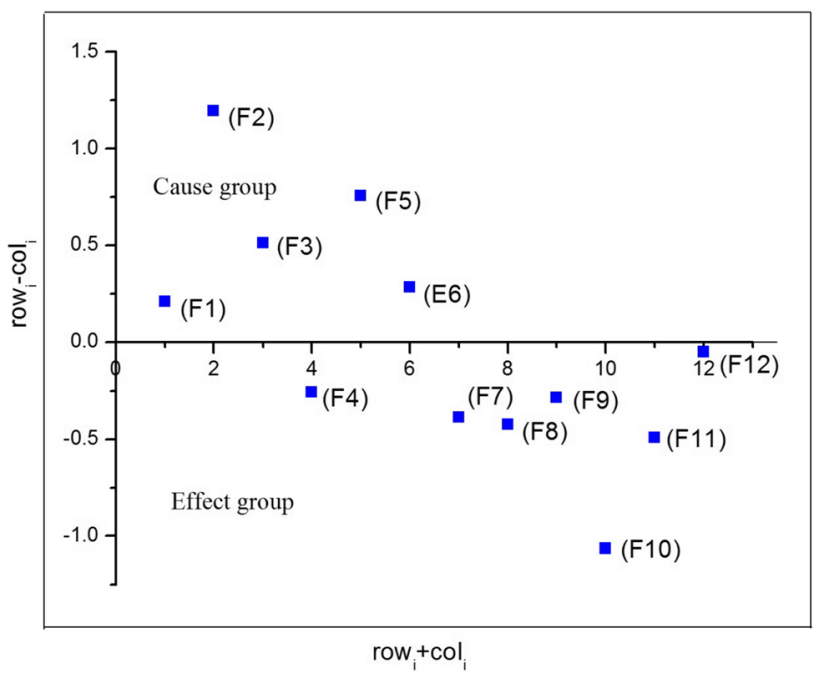

Figure 2. Cause and effect graph (CEG)

\section{Results and discussion}

In this work, a fuzzy DEMATEL is proposed to recognize highly influential risk factors affecting EHS in the healthcare industry. EHS in the healthcare industry
Table 8. Relative vector for cause group-criteria $\left(\operatorname{Row}_{i}-\mathrm{Col}_{i}\right)$.

\begin{tabular}{lcc}
\hline Rank & Cause group-criteria & Row $_{i}-$ Col $_{i}$ \\
\hline 1 & 2 & 1.197 \\
2 & 5 & 0.756 \\
3 & 3 & 0.511 \\
4 & 6 & 0.283 \\
5 & 1 & 0.21 \\
\hline
\end{tabular}

Table 9. Relative vector for effect group-criteria $\left(\operatorname{Row}_{i}-\mathrm{Col}_{i}\right)$.

\begin{tabular}{lcc}
\hline Rank & Effect group-criteria & Row $_{i}-$ Col $_{i}$ \\
\hline 1 & 10 & -1.064 \\
2 & 11 & -0.492 \\
3 & 8 & -0.424 \\
4 & 7 & -0.385 \\
5 & 9 & -0.284 \\
\hline
\end{tabular}

faces difficulties in daily life as they are difficult to solve. This paper investigates twelve risk factors affecting EHS in the healthcare industry and their interrelationships with each other using fuzzy 
DEMATEL. Figure 2 presents the CEG, which is obtained based on the study conducted.

The order of importance of the 12 risk factors regarding EHS in the healthcare industry through a level of significance $\left(\right.$ Row $\left._{i}+\mathrm{Col}_{i}\right)$ is noted as F8-F1-F7-F9-F11-F4F3-F6-F12-F5-F10-F2. As per $\left(\right.$ Row $_{i}+$ Col $\left._{i}\right)$ the value in the table, Government norms (F8), Process risk (F1) and Hygiene programmes (F7) are the most noteworthy in contrast with other risk factors with values of 6.676, 6.33 and 5.735, respectively. Additionally, Psychological factors (F5), Stake holders (F10) and Factory age (F2) have the least significance, their respective values being 5.508, 3.668 and 3.397. Risk factors like Factory age (F2), Psychological factors (F5), Raw materials (F3), Cultural (F6) and Process risk $(\mathrm{F} 1)$ were classified in the cause group. Specific risk factors like Stakeholders (F10), Emergencies (F11), Government norms (F8), Hygiene programmes (F7), Employee awareness (F9), Engineering-based risk (F4) and Unions (F12) are classified in the effect group using the individual $\left(\operatorname{Row}_{i}-\mathrm{Col}_{i}\right)$ value. A specific investigation of the cause and effect groups fixes risk factors in the subsequent subsets.

\subsection{Discussion of cause group risk factors}

As cause group risk factors are essential, it is critical to centre other factors around them. Among all cause group risk factors, Factory age (F2) $\left(\right.$ Row $_{i}-$ Col $\left._{i}\right)$ has a value of 1.197, suggesting that (F2) has a higher impact on the whole system. However, its $\left(\operatorname{Row}_{i}+\operatorname{Col}_{i}\right)$ value is 3.397, which is small and indicates relatively less impact. Factory age in the healthcare industry indicates that the industry uses old medical equipment and devices, which could lead to enormous health issues. This is the reason why it ranks first in the cause group. Advanced medical equipment and devices are required in the healthcare industry to ensure clean EHS and assure customer happiness by embracing new medical equipment. Therefore, Factory age has a crucial role in improving EHS in the healthcare industry.

The second most elevated risk factor in $\left(\operatorname{Row}_{i}-\mathrm{Col}_{i}\right)$ column is the Psychological factor with a value of 0.756 , which additionally has the capacity to impact other risk factors as given by $\left(\operatorname{Row}_{i}+\mathrm{Col}_{i}\right)$ value equivalent of 5.508. Psychological risks and work-related stress are extremely difficult issues to handle in the firm. They influence significantly on the health of people, administrators and national frugalities. Psychological risks emerge from improper work plan, organization and administration and also weak social background of work and they lead to pessimistic psychological, physical and social consequences such as work-related stress, collapse and unhappiness. These are the reasons why it ranks second in the cause group. Among workers, mental and physical health has equal significance with work ability, but psychological awareness and work ability had similar determinants. Raw materials (F3) with a $\left(\right.$ Row $_{i}-$ Col $\left._{i}\right)$ value of 0.511 ranked third with an impact $\left(\operatorname{Row}_{i}+\mathrm{Col}_{i}\right)$ value equivalent to 4.551. When manufacturing a healthcare product, raw material extraction and handling affect environment, degrading soil, creating water deficiencies and biodiversity issues, and harm environment, leading to global warming. Improper healthcare product use results in poisonous discharges into water, soil and air. Safely and Secured Raw material handling is very much essential for healthcare services. Essentially, the succession of risk factors in the cause group as indicated by their impact on risk factors can be listed as Cultural (F6), with a $\left(\operatorname{Row}_{i}-\mathrm{Col}_{i}\right)$ value of 0.283 . Cultural risks are the accumulation of social values and behaviours existing in an organization that portrays risk judgments for the general administration as well as workers. Misunderstandings, strains and predispositions caused by cultural risks can prompt healthcare product failure as also neglecting to revive culture-related management practices. These are the reasons why it ranks fourth in the cause group. Hence for achieving better performance the cultural risks need to be reduced or controlled. Process risk (F1) with a $\left(\right.$ Row $\left._{i}-C l_{i}\right)$ score of 0.21 has a noteworthy part in the healthcare industry. It is the risk of loss due to failed inward procedures, individuals and systems or due to outside occasions. In the healthcare industry, potential danger to human health and safety is possible as an accident or damage due to repeated strain. Due to this, process risk comes last in the cause group.

\subsection{Discussion of effect group risk factors}

Risk factors in the effect group are affected by different factors. They do not directly affect the system. Of all effect group factors, Stakeholders factor (F10) gets the minimum $\left(\right.$ Row $\left._{i}-\mathrm{Col}_{i}\right)$ score of -1.064 , suggesting that this factor has a high effect. There are people influenced by decision, treatment, system or process. Healthcare industry stakeholders can be individuals, associations or gatherings with associations like an administration, which may change during the process. These are the reasons why it ranks first in the effect group as it helps maintain a strategic distance from this issue and understand the stakeholder's environment and execute stakeholder management plan. The other risk factors, in an order of precedence in the effect group, are Emergencies (F11) with a $\left(\right.$ Row $\left._{i}-\mathrm{Col}_{i}\right)$ value of -0.492 , Government norms (F8) with a $\left(\right.$ Row $_{i}-$ Col $\left._{i}\right)$ score of -0.424 , Hygiene programmes (F7) with a $\left(\right.$ Row $\left._{i}-\mathrm{Col}_{i}\right)$ score of -0.385 , Employee awareness (F9) with a $\left(\right.$ Row $\left._{i}-\mathrm{Col}_{i}\right)$ score of -0.284 , Engineering-based risk (F4) with a $\left(\right.$ Row $\left._{i}-\mathrm{Col}_{i}\right)$ score of -0.258 and Union (F12) with a $\left(\right.$ Row $_{i}-$ Col $\left._{i}\right)$ score of -0.05 . The Factor (F8) is among the best as indicated by a $\left(\operatorname{Row}_{i}+\operatorname{Col}_{i}\right)$ value of 6.676, suggesting the factor's significance. Government fixes norms for high-risk medicines. In a move to upgrade customer awareness and safety of drugs, the health ministry 
affixes marking standards for high-risk medicines, making it mandatory for the healthcare industry. However, many industries do not follow standards for high-risk medicines. The new guidelines are applicable to medicines that have a high risk of side effects or are to be used only under medical supervision. As per the standards, the label is on the inner container of such high-risk or sensitive drugs arranged as per schedule ten in the Drugs and Cosmetics rules 2018. Also, the healthcare industry follows Environmental Protection Act (1986) with the aim of protecting and improving the environment.

Emergencies (F11) are the most viable factor in the effect group. They are a circumstance representing an immediate risk to health, life, property or environment. Emergency care services are the regular issue looked at by the healthcare industry. To overcome this issue, an industry can get ready with an Emergency Response Plan, while creating and keeping up an emergency preparedness communication plan that conforms to government, state and local laws. In case of any emergency, industries can utilize this plan. Factors are categorized as cause and effect groups as per discoveries and are illustrative of execution and result directions. To acquire the wanted impact, constant development is needed for the cause group. Lastly, the study may encourage professionals/decision analysts to think about different key factors to develop EHS in industries.

\section{Managerial implications}

The findings of this work reveal that Factory age (F2) is the most influential factor and hence must be given due consideration for achieving the success of EHS in healthcare industry. The research outcomes are helpful for managers and top authorities in the industry to improve EHS as a justification after identification of this factor. Latest and advanced medical equipment and devices are required for the healthcare industry to ensure clean environmental health. Safety is an essential factor and should be tended to first. The healthcare industry cannot give equal weight to all factors simultaneously. However, it is mandatory to ensure equal weight to all factors. In this research, a fuzzy DEMATEL is proposed, which has many implications for the practitioners and researchers in healthcare sector in India.

\section{Conclusion}

There is an extraordinary potential for EHS in a country like India as far as favourable conditions, environmental pollution and clean environment are concerned. However, implementing EHS activities and projects is not simple. This work endeavours to put into practice successful EHS by assessing risk factors connected to health and safety in the healthcare industry. This paper proposes a decision model and elucidates interrelations among factors, in addition to outlining their causal interactions through a causal diagram. The final causal effect diagram shows a detailed picture of the collaborations among factors in developing EHS in the healthcare industry. This will be valuable for policy makers to create systems dealing with health and safety and to make decisions effectively. A fuzzy DEMATEL method to examine the impact and powerful communications among factors is proposed. Fuzzy DEMATEL is helpful in managing human subjectivity, while DEMATEL empowers building up a basic model to comprehend and investigate causal collaborations among key EHS factors.

The suggested factor analysis based on fuzzy DEMATEL method is deliberated upon with respect to India. In view of literature and information sources from experts, this paper has listed 12 factors with regard to effective EHS in the healthcare industry. Fuzzy DEMATEL is used to dissect identified factors. Then the cause and effect group is framed. Risk factors, viz., Factory age (E2), Psychological (E5), Raw materials (E3), cultural (E6) and Process risk (E1), are slotted into the cause group, which aims to ensure EHS in the healthcare industry. The remaining factors, namely Stakeholders (E10), Emergencies (E11), Government norms (E8), Hygiene programmes (E7), Employee awareness (E9), Engineering-based risk (E4) and Union (E12), fall into the effect group; they should be enhanced to increase EHS in the healthcare industry.

This study has some limitations. The 12 risk factors related to EHS in the healthcare industry are recognized in this paper, but not the others. The identification of risk factors could be a challenge from a futuristic point of view. In the present research, all pairwise comparisons in fuzzy DEMATEL methodology are formed based on the views of specialists. However, they could be prejudiced in their views. In future research, in addition to the 12 identified risk factors, a few more factors related to EHS could be identified. The implementation of other computing tools or ranking methods like ANP, TOPSIS and IRP may ensure good bonding to overcome this limitation. The number of experts considered in this study is limited to four experts. In future, though fuzzy set theory manages uncertainty, it is restricted to managing fuzziness, and hence further addition can be made to the grey theory for further investigations.

\section{Appendix A. Questionnaire}

Note: A questionnaire is framed for the intention of performing survey among the experts to assess factors affecting EHS in healthcare industry as part of this research work. The collected data will be used only for educational/ research work. The data acquired through the survey will 
not be shared with others at any point of time. The data collected will not be disclosed in social media as well as the competitors in the same field. For this research work, I will genuinely thank if you spend your precious time for giving rating. Your involvement will immensely aid me to attain the positive goals of my research work; in addition, your experience, ability and skill in the field will contribute towards importance addition to this work (table A1).

\section{Appendix B}

The fuzzy assessment data provided by the experts for pairwise comparisons between key risk factors of Environmental Health and Safety in healthcare industries. See appendix tables B1, B2, B3 and B4.

Table A1. Fuzzy linguistic scale used in this research.

\begin{tabular}{lcc}
\hline $\begin{array}{l}\text { Five-point score for } \\
\text { decision makers } \\
\text { preference }\end{array}$ & $\begin{array}{c}\text { Linguistic } \\
\text { constants and } \\
\text { their description }\end{array}$ & $\begin{array}{c}\text { Trapezoidal fuzzy } \\
\text { numbers (TrapFN) for } \\
\text { equivalent scores }\end{array}$ \\
\hline 0 & $\begin{array}{c}\text { No influence } \\
\text { (No) } \\
\text { Very low } \\
\text { influence (VL) } \\
\text { Low influence } \\
(\text { L) }\end{array}$ & $(0,0,0.1,0.2)$ \\
3 & $\begin{array}{c}(0.1,0.2,0.3,0.4) \\
\text { High influence } \\
(\mathrm{H})\end{array}$ & $(0.5,0.6,0.0 .7,0.0 .6)$ \\
4 & $\begin{array}{c}\text { Very high } \\
\text { influence } \\
(\mathrm{VH})\end{array}$ & $(0.7,0.8,0.9,1)$ \\
\hline
\end{tabular}

Please tick $[\checkmark]$ any one of ratings that you feel suitable for each item (see table A1)

\begin{tabular}{|c|l|l|l|l|l|l|l|l|l|l|l|l|}
\hline & \multicolumn{9}{|c|}{ Linguistic constants } \\
\hline & Fisk factors & F2 & F3 & F4 & F5 & F6 & F7 & F8 & F9 & F10 & F11 & F12 \\
\hline Process risk (F1) & & & & & & & & & & & & \\
\hline Factory age (F2) & & & & & & & & & & & & \\
\hline Raw materials (F3) & & & & & & & & & & & & \\
\hline Engineering-based risk & & & & & & & & & & & & \\
\hline (F4) & & & & & & & & & & & & \\
\hline Psychological (F5) & & & & & & & & & & & & \\
\hline Cultural (F6) & & & & & & & & & & & & \\
\hline Hygienic programme (F7) & & & & & & & & & & & & \\
\hline Government norms (F8) & & & & & & & & & & & & \\
\hline Employee awareness (F9) & & & & & & & & & & & & \\
\hline Stakeholders (F10) & & & & & & & & & & & & \\
\hline Emergencies (F11) & & & & & & & & & & & & \\
\hline Union (F12) & & & & & & & & & & & & \\
\hline
\end{tabular}




\section{Personal information:}

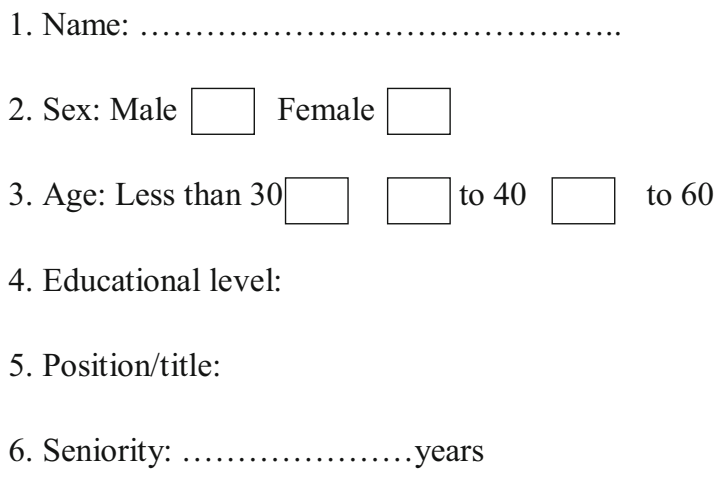

Thank you very much for your time and effort in filling this questionnaire.

Table B1. The fuzzy assessment data provided by Expert 1 .

\begin{tabular}{|c|c|c|c|c|c|c|}
\hline & F1 & $\mathrm{F} 2$ & $\mathrm{~F} 3$ & $\mathrm{~F} 4$ & F5 & F6 \\
\hline $\mathrm{F} 1$ & $0.00,0.00,0.10,0.20$ & $0.70,0.80,0.90,1.00$ & $0.70,0.80,0.90,1.00$ & $0.70,0.80,0.90,1.00$ & $0.00,0.00,0.10,0.20$ & $0.00,0.00,0.10,0.20$ \\
\hline $\mathrm{F} 2$ & $0.50,0.60,0.70,0.80$ & $0.00,0.00,0.10,0.20$ & $0.00,0.00,0.10,0.20$ & $0.50,0.60,0.70,0.80$ & $0.30,0.40,0.50,0.60$ & $0.10,0.20,0.30,0.40$ \\
\hline F3 & $0.70,0.80,0.90,1.00$ & $0.00,0.00,0.10,0.20$ & $0.00,0.00,0.10,0.20$ & $0.30,0.40,0.50,0.60$ & $0.00,0.00,0.10,0.20$ & $0.00,0.00,0.10,0.20$ \\
\hline $\mathrm{F} 4$ & $0.70,0.80,0.90,1.00$ & $0.00,0.00,0.10,0.20$ & $0.00,0.00,0.10,0.20$ & $0.00,0.00,0.10,0.20$ & $0.00,0.00,0.10,0.20$ & $0.00,0.00,0.10,0.20$ \\
\hline F5 & $0.30,0.40,0.50,0.60$ & $0.00,0.00,0.10,0.20$ & $0.00,0.00,0.10,0.20$ & $0.00,0.00,0.10,0.20$ & $0.00,0.00,0.10,0.20$ & $0.70,0.80,0.90,1.00$ \\
\hline F6 & $0.10,0.20,0.30,0.40$ & $0.00,0.00,0.10,0.20$ & $0.00,0.00,0.10,0.20$ & $0.00,0.00,0.10,0.20$ & $0.70,0.80,0.90,1.00$ & $0.00,0.00,0.10,0.20$ \\
\hline F7 & $0.70,0.80,0.90,1.00$ & $0.00,0.00,0.10,0.20$ & $0.70,0.80,0.90,1.00$ & $0.70,0.80,0.90,1.00$ & $0.30,0.40,0.50,0.60$ & $0.30,0.40,0.50,0.60$ \\
\hline F8 & $0.50,0.60,0.70,0.80$ & $0.00,0.00,0.10,0.20$ & $0.50,0.60,0.70,0.80$ & $0.70,0.80,0.90,1.00$ & $0.00,0.00,0.10,0.20$ & $0.00,0.00,0.10,0.20$ \\
\hline F9 & $0.50,0.60,0.70,0.80$ & $0.00,0.00,0.10,0.20$ & $0.00,0.00,0.10,0.20$ & $0.30,0.40,0.50,0.60$ & $0.50,0.60,0.70,0.80$ & $0.70,0.80,0.90,1.00$ \\
\hline F10 & $0.00,0.00,0.10,0.20$ & $0.00,0.00,0.10,0.20$ & $0.00,0.00,0.10,0.20$ & $0.00,0.00,0.10,0.20$ & $0.00,0.00,0.10,0.20$ & $0.30,0.40,0.50,0.60$ \\
\hline F11 & $0.50,0.60,0.70,0.80$ & $0.00,0.00,0.10,0.20$ & $0.70,0.80,0.90,1.00$ & $0.70,0.80,0.90,1.00$ & $0.00,0.00,0.10,0.20$ & $0.00,0.00,0.10,0.20$ \\
\hline \multirow[t]{2}{*}{ F12 } & $0.00,0.00,0.10,0.20$ & $0.30,0.40,0.50,0.60$ & $0.00,0.00,0.10,0.20$ & $0.00,0.00,0.10,0.20$ & $0.70,0.80,0.90,1.00$ & $0.70,0.80,0.90,1.00$ \\
\hline & F7 & F8 & F9 & F10 & F11 & $\mathrm{F} 12$ \\
\hline$F 1$ & $0.50,0.60,0.70,0.80$ & $0.70,0.80,0.90,1.00$ & $0.30,0.40,0.50,0.60$ & $0.50,0.60,0.70,0.80$ & $0.70,0.80,0.9$ & $0.00,0.00,0.10,0.20$ \\
\hline $\mathrm{F} 2$ & $0.30,0.40,0.50,0.60$ & $0.00,0.00,0.10,0.20$ & $0.30,0.40,0.50,0.60$ & $0.00,0.00,0.10,0.20$ & $0.30,0.40,0.50,0.60$ & $0.50,0.60,0.70,0.80$ \\
\hline F3 & $0.70,0.80,0.90,1.00$ & $0.70,0.80,0.90,1.00$ & $0.00,0.00,0.10,0.20$ & $0.30,0.40,0.50,0.60$ & $0.70,0.80,0.90,1.00$ & $0.00,0.00,0.10,0.20$ \\
\hline $\mathrm{F} 4$ & $0.70,0.80,0.90,1.00$ & $0.70,0.80,0.90,1.00$ & $0.50,0.60,0.70,0.80$ & $0.00,0.00,0.10,0.20$ & $0.50,0.60,0.70,0.80$ & $0.00,0.00,0.10,0.20$ \\
\hline F5 & $0.30,0.40,0.50,0.60$ & $0.30,0.40,0.50,0.60$ & $0.70,0.80,0.90,1.00$ & $0.30,0.40,0.50,0.60$ & $0.30,0.40,0.50,0.60$ & $0.70,0.80,0.90,1.00$ \\
\hline F6 & $0.30,0.40,0.50,0.60$ & $0.30,0.40,0.50,0.60$ & $0.70,0.80,0.90,1.00$ & $0.50,0.60,0.70,0.80$ & $0.10,0.20,0.30,0.40$ & $0.70,0.80,0.90,1.00$ \\
\hline F7 & $0.00,0.00,0.10,0.20$ & $0.70,0.80,0.90,1.00$ & $0.30,0.40,0.50,0.60$ & $0.00,0.00,0.10,0.20$ & $0.00,0.00,0.10,0.20$ & $0.10,0.20,0.30,0.40$ \\
\hline F8 & $0.70,0.80,0.90,1.00$ & $0.00,0.00,0.10,0.20$ & $0.70,0.80,0.90,1.00$ & $0.70,0.80,0.90,1.00$ & $0.70,0.80,0.90,1.00$ & $0.50,0.60,0.70,0.80$ \\
\hline F9 & $0.50,0.60,0.70,0.80$ & $0.10,0.20,0.30,0.40$ & $0.00,0.00,0.10,0.20$ & $0.00,0.00,0.10,0.20$ & $0.30,0.40,0.50,0.60$ & $0.70,0.80,0.90,1.00$ \\
\hline F10 & $0.00,0.00,0.10,0.20$ & $0.50,0.60,0.70,0.80$ & $0.00,0.00,0.10,0.20$ & $0.00,0.00,0.10,0.20$ & $0.50,0.60,0.70,0.80$ & $0.00,0.00,0.10,0.20$ \\
\hline F11 & $0.30,0.40,0.50,0.60$ & $0.70,0.80,0.90,1.00$ & $0.30,0.40,0.50,0.60$ & $0.70,0.80,0.90,1.00$ & $0.00,0.00,0.10,0.20$ & $0.00,0.00,0.10,0.20$ \\
\hline F12 & $0.00,0.00,0.10,0.20$ & $0.50,0.60,0.70,0.80$ & $0.70,0.80,0.90,1.00$ & $0.00,0.00,0.10,0.20$ & $0.00,0.00,0.10,0.20$ & $0.00,0.00,0.10,0.20$ \\
\hline
\end{tabular}


Table B2. The fuzzy assessment data provided by Expert 2 .

\begin{tabular}{|c|c|c|c|c|c|c|}
\hline & $\mathrm{F} 1$ & $\mathrm{~F} 2$ & F3 & $\mathrm{F} 4$ & F5 & F6 \\
\hline $\bar{F} 1$ & $0.00,0.00,0.10,0.20$ & $0.70,0.80,0.90,1.00$ & $70,0.80,0.90,1.00$ & $0.70,0.80,0.90,1.00$ & $0.00,0.00,0.10,0.20$ & $0.00,0.00,0.10,0.20$ \\
\hline $\mathrm{F} 2$ & $0.30,0.40,0.50,0.60$ & $0.00,0.00,0.10,0.20$ & $00,0.00,0.10,0.20$ & $.50,0.60,0.70,0.80$ & $0.30,0.40,0.50$ & $0.10,0.20,0.30,0.40$ \\
\hline F3 & $0.70,0.80,0.90,1.00$ & $0.00,0.00,0.10,0.20$ & $0.00,0.00,0.10,0.20$ & $0.30,0.40,0.50,0.60$ & $0.00,0.00,0.10,0.20$ & $0.00,0.00,0.10,0.20$ \\
\hline F4 & $0.70,0.80,0.90,1.00$ & $0.00,0.00,0.10,0.20$ & $0.00,0.00,0.10,0.20$ & $0.00,0.00,0.10,0.20$ & $0.00,0.00,0.10,0.20$ & $0.00,0.00,0.10,0.20$ \\
\hline F5 & $0.30,0.40,0.50,0.60$ & $0.00,0.00,0.10,0.20$ & $0.00,0.00,0.10,0.20$ & $0.00,0.00,0.10,0.20$ & $0.00,0.00,0.10,0.20$ & $0.70,0.80,0.90,1.00$ \\
\hline F6 & $0.10,0.20,0.30,0.40$ & $0.00,0.00,0.10,0.20$ & $0.00,0.00,0.10,0.20$ & $0.00,0.00,0.10,0.20$ & $0.70,0.80,0.90,1.00$ & $0.00,0.00,0.10,0.20$ \\
\hline F7 & $0.50,0.60,0.70,0.80$ & $0.00,0.00,0.10,0.20$ & $0.70,0.80,0.90,1.00$ & $0.50,0.60,0.70,0.80$ & $0.30,0.40,0.50,0.60$ & $0.30,0.40,0.50,0.60$ \\
\hline F8 & $0.50,0.60,0.70,0.80$ & $0.00,0.00,0.10,0.20$ & $0.30,0.40,0.50,0.60$ & $0.70,0.80,0.90,1.00$ & $0.00,0.00,0.10,0.20$ & $0.00,0.00,0.10,0.20$ \\
\hline F9 & $0.50,0.60,0.70,0.80$ & $0.00,0.00,0.10,0.20$ & $0.00,0.00,0.10,0.20$ & $0.30,0.40,0.50,0.60$ & $0.30,0.40,0.50,0.60$ & $0.70,0.80,0.90,1.00$ \\
\hline F10 & $0.00,0.00,0.10,0.20$ & $0.00,0.00,0.10,0.20$ & $0.00,0.00,0.10,0.20$ & $0.00,0.00,0.10,0.20$ & $0.00,0.00,0.10,0.20$ & $0.30,0.40,0.50,0.60$ \\
\hline F11 & $0.50,0.60,0.70,0.80$ & $0.00,0.00,0.10,0.20$ & $0.70,0.80,0.90,1.00$ & $0.70,0.80,0.90,1.00$ & $0.00,0.00,0.10,0.20$ & $0.00,0.00,0.10,0.20$ \\
\hline \multirow[t]{2}{*}{$\underline{F 12}$} & $0.00,0.00,0.10,0.20$ & $0.30,0.40,0.50,0.60$ & $0.00,0.00,0.10,0.20$ & $0.00,0.00,0.10,0.20$ & $0.70,0.80,0.90,1.00$ & $0.70,0.80,0.90,1.00$ \\
\hline & F7 & F8 & F9 & F10 & F11 & F12 \\
\hline $\mathrm{F} 1$ & $0.50,0.60,0.70,0.80$ & $0.70,0.80,0.90,1.00$ & $.30,0.40,0.50,0.60$ & $0.50,0.60,0.70$ & $0.70,0.80,0.9$ & $0.00,0.00,0.10,0.20$ \\
\hline $\mathrm{F} 2$ & $0.30,0.40,0.50,0.60$ & $0.10,0.20,0.30,0.40$ & $0.30,0.40,0.50,0.60$ & $0.00,0.00,0.10,0.20$ & $0.30,0.40,0.50,0.60$ & $0.50,0.60,0.70,0.80$ \\
\hline F3 & $0.50,0.60,0.70,0.80$ & $0.70,0.80,0.90,1.00$ & $0.00,0.00,0.10,0.20$ & $0.30,0.40,0.50,0.60$ & $0.70,0.80,0.90,1.00$ & $0.00,0.00,0.10,0.20$ \\
\hline F4 & $0.70,0.80,0.90,1.00$ & $0.70,0.80,0.90,1.00$ & $0.50,0.60,0.70,0.80$ & $0.00,0.00,0.10,0.20$ & $0.50,0.60,0.70,0.80$ & $0.10,0.20,0.30,0.40$ \\
\hline F5 & $0.30,0.40,0.50,0.60$ & $0.30,0.40,0.50,0.60$ & $0.50,0.60,0.70,0.80$ & $0.30,0.40,0.5$ & $0.30,0.40,0.5$ & $0.70,0.80,0.90,1.00$ \\
\hline F6 & $0.30,0.40,0.50,0.60$ & $0.30,0.40,0.50,0.60$ & $0.70,0.80,0.90,1.00$ & $0.50,0.60,0.70,0.80$ & $0.10,0.20,0.30,0.40$ & $0.50,0.60,0.70,0.80$ \\
\hline F7 & $0.00,0.00,0.10,0.20$ & $0.70,0.80,0.90,1.00$ & $0.30,0.40,0.50,0.60$ & $0.00,0.00,0.10,0.20$ & $0.00,0.00,0.10,0.20$ & $0.10,0.20,0.30,0.40$ \\
\hline F8 & $0.70,0.80,0.90,1.00$ & $0.00,0.00,0.10,0.20$ & $0.70,0.80,0.90,1.00$ & $0.70,0.80,0.90,1.00$ & $0.70,0.80,0.90,1.00$ & $0.50,0.60,0.70,0.80$ \\
\hline F9 & $0.50,0.60,0.70,0.80$ & $0.10,0.20,0.30,0.40$ & $0.00,0.00,0.10,0.20$ & $0.00,0.00,0.10,0.20$ & $0.30,0.40,0.50,0.60$ & $0.70,0.80,0.90,1.00$ \\
\hline F10 & $0.00,0.00,0.10,0.20$ & $0.50,0.60,0.70,0.80$ & $0.00,0.00,0.10,0.20$ & $0.00,0.00,0.10,0.20$ & $0.50,0.60,0.70,0.80$ & $0.00,0.00,0.10,0.20$ \\
\hline F11 & $0.30,0.40,0.50,0.60$ & $0.50,0.60,0.70,0.80$ & $0.30,0.40,0.50,0.60$ & $0.70,0.80,0.90,1.00$ & $0.00,0.00,0.10,0.20$ & $0.00,0.00,0.10,0.20$ \\
\hline F12 & $0.00,0.00,0.10,0.20$ & $0.50,0.60,0.70,0.80$ & $0.70,0.80,0.90,1.00$ & $0.00,0.00,0.10,0.20$ & $0.00,0.00,0.10,0.20$ & $0.00,0.00,0.10,0.20$ \\
\hline
\end{tabular}

Table B3. The fuzzy assessment data provided by Expert 3.

\begin{tabular}{|c|c|c|c|c|c|c|}
\hline & $\mathrm{F} 1$ & $\mathrm{~F} 2$ & $\mathrm{~F} 3$ & $\mathrm{~F} 4$ & F5 & F6 \\
\hline $\mathrm{F} 1$ & $00,0.00,0.10,0.20$ & $70,0.80,0$ & $70,0.80$, & 00 & $00,0.10,0.20$ & .00 \\
\hline $\mathrm{F} 2$ & $0.50,0.60,0.70,0.80$ & $00,0.00,0.10,0.20$ & $00,0.00,0.10,0.20$ & $70,0.80,0.90,1.00$ & $10,0.20,0.30,0.40$ & $.30,0.40,0.50,0.60$ \\
\hline F3 & $0.70,0.80,0.90,1.00$ & $00,0.00,0.10,0.20$ & $00,0.00,0.10,0$ & $30,0.40,0$ & $.00,0.00,0.10,0.20$ & $0.00,0.00,0$ \\
\hline $\mathrm{F} 4$ & $0.70,0.80,0.90,1.00$ & $00,0.00,0.10,0.20$ & $00,0.00,0.10,0.20$ & $0.00,0.00,0.10,0.20$ & $0.00,0.00,0.10,0.20$ & $0.00,0.00,0.10,0.20$ \\
\hline F5 & $0.30,0.40,0.50,0.60$ & $00,0.00,0.10,0.20$ & $.00,0.00,0.10,0.20$ & $0.00,0.00,0.10,0.20$ & $0.00,0.00,0.10,0.20$ & $0.70,0.80,0.90,1.00$ \\
\hline F6 & $0.10,0.20,0.30,0.40$ & $00,0.10,0.20$ & 20 & .20 & .00 & $0,0.20$ \\
\hline F7 & $0.50,0.60,0.70,0.80$ & $0.00,0.00,0.10,0.20$ & $0.70,0.80,0.90,1.00$ & $0.50,0.60,0.70,0.80$ & $0.30,0.40,0.50,0.60$ & $0.30,0.40,0.50,0.60$ \\
\hline F8 & $0.50,0.60,0.70,0.80$ & $.00,0.00,0.10,0.20$ & $.30,0.40,0.50,0.60$ & $0.70,0.80,0$. & $0.00,0.00,0$ & م \\
\hline F9 & $0.50,0.60,0.70,0.80$ & $0.00,0.00,0.10,0.20$ & $0.00,0.00,0.1$ & $.40,0.5$ & $0.30,0.40,0.5$ & $0.70,0.80,0.90,1.00$ \\
\hline F10 & $0.00,0.00,0.10,0.20$ & $00,0.00,0$. & $.00,0.00,0$ & 0.00 & $0.00,0.00$ & 0.30 \\
\hline F11 & 0.70 & 20 & 00 & 60 & 0.0 & $0.00,0.0$ \\
\hline \multirow[t]{2}{*}{ F12 } & $0.00,0.00,0.10,0.20$ & $0.30,0.40,0.50,0.60$ & $0.00,0.00,0.10,0.20$ & $0.00,0.00,0.10,0.20$ & $0.70,0.80,0.90,1.00$ & $0.70,0.80,0.90,1.00$ \\
\hline & F7 & F8 & F9 & F10 & F11 & F12 \\
\hline $\mathrm{F} 1$ & 80 & & & & & \\
\hline $\mathrm{F} 2$ & $0.30,0.40,0.5$ & $0.00,0.00,0$ & 0.30 & 0.0 & 0.30 , & 0.50 \\
\hline F3 & $0.70,0$. & $0.70,0$ & $0.00,0.00,0$ & 60 & $0.70,0.80,0.9$ & $0.00,0.00,0.10,0.20$ \\
\hline $\mathrm{F} 4$ & $0.70,0.80,0.90,1.00$ & $0.70,0.80,0.90,1.00$ & $0.50,0.60,0.70,0.80$ & $0.00,0.00,0.10,0.20$ & $0.50,0.60,0.7$ & $0.10,0.20,0.30,0.40$ \\
\hline F5 & $0.30,0.40,0.50,0.60$ & $0.30,0.40,0$ & $0.50,0.60,0$ & $0.30,0.40,0$ & $0.30,0.40,0.50,0.60$ & $0.70,0.80,0.90,1.00$ \\
\hline F6 & $0.30,0.40,0.50,0.60$ & $0.30,0.40,0.50,0.60$ & $0.70,0.80,0.90,1.00$ & $0.50,0.60,0.70,0.80$ & $0.10,0.20,0.30,0.40$ & $0.50,0.60,0.70,0.80$ \\
\hline F7 & $0.00,0.00,0.10,0.20$ & $0.70,0.80,0.90,1.00$ & $0.30,0.40,0.50,0.60$ & $0.00,0.00,0.10,0.20$ & $0.00,0.00,0.10,0.20$ & $0.10,0.20,0.30,0.40$ \\
\hline F8 & $0.70,0.80,0.90,1.00$ & $0.00,0.00,0.10,0.20$ & $0.70,0.80,0.90,1.00$ & $0.70,0.80,0.90,1.00$ & $0.70,0.80,0.90,1.00$ & $0.50,0.60,0.70,0.80$ \\
\hline F9 & $0.70,0.80,0.90,1.00$ & $0.30,0.40,0.50,0.60$ & $0.00,0.00,0.10,0.20$ & $0.00,0.00,0.10,0.20$ & $0.50,0.60,0.70,0.80$ & $0.70,0.80,0.90,1.00$ \\
\hline F10 & $0.00,0.00,0.10,0.20$ & $0.50,0.60,0.70,0.80$ & $0.00,0.00,0.10,0.20$ & $0.00,0.00,0.10,0.20$ & $0.50,0.60,0.70,0.80$ & $0.00,0.00,0.10,0.20$ \\
\hline F11 & & & & & & $0.00,0.00,0.10,0.20$ \\
\hline F12 & $0.00,0.00,0.10,0.20$ & $0.50,0.60,0.70,0.80$ & $0.70,0.80,0.90,1.00$ & $0.00,0.00,0.10,0.20$ & $0.00,0.00,0.10,0.20$ & $0.00,0.00,0.10,0.20$ \\
\hline
\end{tabular}


Table B4. The fuzzy assessment data provided by Expert 4 .

\begin{tabular}{|c|c|c|c|c|c|c|}
\hline & $\mathrm{F} 1$ & $\mathrm{~F} 2$ & $\mathrm{~F} 3$ & $\mathrm{~F} 4$ & F5 & F6 \\
\hline $\mathrm{F} 1$ & $0.00,0.00,0.10,0.20$ & $.70,0.80,0.90,1.00$ & $0.70,0.80,0.90,1.00$ & $0.70,0.80,0.90,1.00$ & $0.30,0.40,0.50,0.60$ & $0.00,0.00,0.10,0.20$ \\
\hline $\mathrm{F} 2$ & $0.50,0.60,0.70,0.80$ & $0.00,0.00,0.10,0.20$ & $0.00,0.00,0.10,0.20$ & $0.70,0.80,0.90,1.00$ & $0.10,0.20,0.30,0.40$ & $0.30,0.40,0.50,0.60$ \\
\hline F3 & $0.70,0.80,0.90,1.00$ & $0.00,0.00,0.10,0.20$ & $0.00,0.00,0.10,0.20$ & $0.30,0.40,0.50,0.60$ & $0.00,0.00,0.10,0.20$ & $0.00,0.00,0.10,0.20$ \\
\hline F4 & $0.70,0.80,0.90,1.00$ & $0.00,0.00,0.10,0.20$ & $0.00,0.00,0.10,0.20$ & $0.00,0.00,0.10,0.20$ & $0.00,0.00,0.10,0.20$ & $0.00,0.00,0.10,0.20$ \\
\hline F5 & $0.30,0.40,0.50,0.60$ & $0.00,0.00,0.10,0.20$ & $0.00,0.00,0.10,0.20$ & $0.00,0.00,0.10,0.20$ & $0.00,0.00,0.10,0.20$ & $0.70,0.80,0.90,1.00$ \\
\hline F6 & $0.10,0.20,0.30,0.40$ & $0.00,0.00,0.10,0.20$ & $0.00,0.00,0.10,0.20$ & $0.00,0.00,0.10,0.20$ & $0.70,0.80,0.90,1.00$ & $0.00,0.00,0.10,0.20$ \\
\hline F7 & $0.70,0.80,0.90,1.00$ & $0.00,0.00,0.10,0.20$ & $0.30,0.40,0.50,0.60$ & $0.50,0.60,0.70,0.80$ & $0.30,0.40,0.50,0.60$ & $0.30,0.40,0.50,0.60$ \\
\hline F8 & $0.50,0.60,0.70,0.80$ & $0.00,0.00,0.10,0.20$ & $0.30,0.40,0.50,0.60$ & $0.70,0.80,0.90,1.00$ & $0.00,0.00,0.10,0.20$ & $0.00,0.00,0.10,0.20$ \\
\hline F9 & $0.30,0.40,0.50,0.60$ & $0.00,0.00,0.10,0.20$ & $0.00,0.00,0.10,0.20$ & $0.30,0.40,0.50,0.60$ & $0.30,0.40,0.50,0.60$ & $0.70,0.80,0.90,1.00$ \\
\hline F10 & $0.00,0.00,0.10,0.20$ & $0.00,0.00,0.10,0.20$ & $0.00,0.00,0.10,0.20$ & $0.00,0.00,0.10,0.20$ & $0.00,0.00,0.10,0.20$ & $0.30,0.40,0.50,0.60$ \\
\hline F11 & $0.30,0.40,0.50,0.60$ & $0.00,0.00,0.10,0.20$ & $0.50,0.60,0.70,0.80$ & $0.30,0.40,0.50,0.60$ & $0.00,0.00,0.10,0.20$ & $0.00,0.00,0.10,0.20$ \\
\hline \multirow[t]{2}{*}{ F12 } & $0.00,0.00,0.10,0.20$ & $0.30,0.40,0.50,0.60$ & $0.00,0.00,0.10,0.20$ & $0.00,0.00,0.10,0.20$ & $0.70,0.80,0.90,1.00$ & $0.70,0.80,0.90,1.00$ \\
\hline & F7 & F8 & F9 & F10 & F11 & F12 \\
\hline 1 & $0.50,0.60,0.70,0.80$ & $0.70,0.80,0.90,1.00$ & $0.30,0.40,0.50,0.60$ & $0.50,0.60,0.70,0.80$ & $0.70,0.80,0.90,1.00$ & $0.00,0.00,0.10,0.20$ \\
\hline $\mathrm{F} 2$ & $0.30,0.40,0.50,0.60$ & $0.00,0.00,0.10,0.20$ & $0.30,0.40,0.50,0.60$ & $0.00,0.00,0.10,0.20$ & $0.30,0.40,0.50,0.60$ & $0.50,0.60,0.70,0.80$ \\
\hline F3 & $0.70,0.80,0.90,1.00$ & $0.70,0.80,0.90,1.00$ & $0.00,0.00,0.10,0.20$ & $0.30,0.40,0.50,0.60$ & $0.70,0.80,0.90,1.00$ & $0.00,0.00,0.10,0.20$ \\
\hline F4 & $0.70,0.80,0.90,1.00$ & $0.70,0.80,0.90,1.00$ & $0.50,0.60,0.70,0.80$ & $0.00,0.00,0.10,0.20$ & $0.50,0.60,0.70,0.80$ & $0.10,0.20,0.30,0.40$ \\
\hline F5 & $0.30,0.40,0.50,0.60$ & $0.30,0.40,0.50,0.60$ & $0.50,0.60,0.70,0.80$ & $0.30,0.40,0.50,0.60$ & $0.30,0.40,0.50,0.60$ & $0.70,0.80,0.90,1.00$ \\
\hline F6 & $0.30,0.40,0.50,0.60$ & $0.30,0.40,0.50,0.60$ & $0.70,0.80,0.90,1.00$ & $0.50,0.60,0.70,0.80$ & $0.10,0.20,0.30,0.40$ & $0.50,0.60,0.70,0.80$ \\
\hline F7 & $0.00,0.00,0.10,0.20$ & $0.70,0.80,0.90,1.00$ & $0.30,0.40,0.50,0.60$ & $0.00,0.00,0.10,0.20$ & $0.00,0.00,0.10,0.20$ & $0.10,0.20,0.30,0.40$ \\
\hline F8 & $0.70,0.80,0.90,1.00$ & $0.00,0.00,0.10,0.20$ & $0.30,0.40,0.50,0.60$ & $0.70,0.80,0.90,1.00$ & $0.70,0.80,0.90,1.00$ & $0.50,0.60,0.70,0.80$ \\
\hline F9 & $0.50,0.60,0.70,0.80$ & $0.30,0.40,0.50,0.60$ & $0.00,0.00,0.10,0.20$ & $0.00,0.00,0.10,0.20$ & $0.50,0.60,0.70,0.80$ & $0.70,0.80,0.90,1.00$ \\
\hline F10 & $0.00,0.00,0.10,0.20$ & $0.50,0.60,0.70,0.80$ & $0.00,0.00,0.10,0.20$ & $0.00,0.00,0.10,0.20$ & $0.50,0.60,0.70,0.80$ & $0.00,0.00,0.10,0.20$ \\
\hline F11 & $0.30,0.40,0.50,0.60$ & $0.50,0.60,0.70,0.80$ & $0.30,0.40,0.50,0.60$ & $0.70,0.80,0.90,1.00$ & $0.00,0.00,0.10,0.20$ & $0.00,0.00,0.10,0.20$ \\
\hline F12 & $0.00,0.00,0.10,0.20$ & $0.50,0.60,0.70,0.80$ & $0.70,0.80,0.90,1.00$ & $0.00,0.00,0.10,0.20$ & $0.00,0.00,0.10,0.20$ & $0.00,0.00,0.10,0.20$ \\
\hline
\end{tabular}

\section{References}

[1] Kamath K, Shabaraya A R and Subramanyam E V S 2014 Role of environment health and safety (EHS) in pharmaceutical industry, vol. 46, pp. 34-35

[2] Bond R G, Michaelsen G S and Deroos R (Eds.) 1973 Environmental health and safety in health-care facilities

[3] Bourbonnais R, Brisson C, Vinet A, Vézina M and Lower A 2006 Development and implementation of a participative intervention to improve the psychosocial work environment and mental health in an acute care hospital. Occupational and Environmental Medicine 63(5): 326-334

[4] Lundstrom T, Pugliese G, Bartley J, Cox J and Guither C 2002 Organizational and environmental factors that affect worker health and safety and patient outcomes. American Journal of Infection Control 30(2): 93-106

[5] Nieva V F and Sorra J 2003 Safety culture assessment: a tool for improving patient safety in healthcare organizations. BMJ Quality \& Safety 12(Suppl 2): ii17-ii23

[6] Baicker K, Cutler D and Song Z 2010 Workplace wellness programs can generate savings. Health Affairs 29(2): 304-311

[7] Govindarajulu N and Daily B F 2004 Motivating employees for environmental improvement. Industrial Management \& Data Systems 104(4): 364-372

[8] Hignett S, Fray M, Rossi M A, Tamminen-Peter L, Hermann S, Lomi C and Johnsson C 2007 Implementation of the Manual Handling Directive in the healthcare industry in the
European Union for patient handling tasks. International Journal of Industrial Ergonomics 37(5): 415-423

[9] Duijm N J, Fiévez C, Gerbec M, Hauptmanns U and Konstandinidou M 2008 Management of health, safety and environment in process industry. Safety Science 46(6): 908-920

[10] Phimister J R, Oktem U, Kleindorfer P R and Kunreuther H 2003 Near miss incident management in the chemical process industry. Risk Analysis 23(3): 445-459

[11] Shen L Y and Tam V W 2002 Implementation of environmental management in the Hong Kong construction industry. International Journal of Project Management 20(7): $535-543$

[12] Lee J, Mahendra S and Alvarez P J 2010 Nanomaterials in the construction industry: a review of their applications and environmental health and safety considerations. ACS Nano 4(7): 3580-3590

[13] Ilangkumaran $M$, Karthikeyan $M$, Ramachandran $T$, Boopathiraja M and Kirubakaran B 2015 Risk analysis and warning rate of hot environment for foundry industry using hybrid MCDM technique. Safety Science 72: 133-143

[14] Reyes J P, San-José J T, Cuadrado J and Sancibrian R 2014 Health \& Safety criteria for determining the sustainable value of construction projects. Safety Science 62: 221-232

[15] Hatami-Marbini A, Tavana M, Moradi M and Kangi F 2013 A fuzzy group Electre method for safety and health assessment in hazardous waste recycling facilities. Safety Science 51(1): 414-426 
[16] Jozi S A, Shoshtary M T and Zadeh A R K 2015 Environmental risk assessment of dams in construction phase using a multicriteria decision-making (MCDM) method. Human and Ecological Risk Assessment: An International Journal 21(1): 1-16

[17] Zheng G, Zhu N, Tian Z, Chen Y and Sun B 2012 Application of a trapezoidal fuzzy AHP method for work safety evaluation and early warning rating of hot and humid environments. Safety Science 50(2): 228-239

[18] Gupta V K and Thakkar J J 2018 A quantitative risk assessment methodology for construction project. Sādhanā 43(7): 116

[19] Rajak A K, Niraj M and Kumar S 2016 Designing of fuzzy expert heuristic models with cost management toward coordinating AHP, fuzzy TOPSIS and FIS approaches. Sädhanā 41(10): 1209-1218

[20] Messelbeck J and Whaley M 1999 Greening the health care supply chain: triggers of change, models for success. Corporate Environmental Strategy 6(1): 39-45

[21] Roberts V 2001 Managing strategic outsourcing in the healthcare industry. Journal of Healthcare Management 46: 239-249

[22] Hale A R and Hovden J 1998 Management and culture: the third age of safety. A review of approaches to organizational aspects of safety, health and environment. Occupational injury: risk, prevention and intervention, pp. 129-165

[23] Kagermann H 2015 Change through digitization-value creation in the age of industry 4.0. In: Management of permanent change. Wiesbaden: Springer Gabler, pp. 23-45

[24] Lam C W, James J T, McCluskey R, Arepalli S and Hunter R L 2006 A review of carbon nanotube toxicity and assessment of potential occupational and environmental health risks. Critical Reviews in Toxicology 36(3): 189-217

[25] Koller G, Fischer U and Hungerbühler K 2000 Assessing safety, health, and environmental impact early during process development. Industrial \& Engineering Chemistry Research 39(4): 960-972

[26] Marx D A and Slonim A D 2003 Assessing patient safety risk before the injury occurs: an introduction to sociotechnical probabilistic risk modelling in health care. BMJ Quality \& Safety 12(Suppl 2): ii33-ii38

[27] Bates D W, Saria S, Ohno-Machado L, Shah A and Escobar G 2014 Big data in health care: using analytics to identify and manage high-risk and high-cost patients. Health Affairs 33(7): 1123-1131

[28] Sauter S L, Murphy L R and Hurrell J J 1990 Prevention of work-related psychological disorders: a national strategy proposed by the National Institute for Occupational Safety and Health (NIOSH). American Psychologist 45(10): 1146

[29] Quinlan R J 2007 Human parental effort and environmental risk. Proceedings of the Royal Society of London B: Biological Sciences 274(1606): 121-125

[30] Betancourt J R, Green A R, Carrillo J E and Owusu AnanehFirempong I I 2016 Defining cultural competence: a practical framework for addressing racial/ethnic disparities in health and health care. Public Health Reports 118(4): 293-302

[31] Plog B A, Niland J and Quinlan P 1996 Fundamentals of industrial hygiene. Ithaca, NY: National Safety Council, pp. 1-7

[32] Stern P C, Dietz T and Black J S 1985 Support for environmental protection: the role of moral norms. Population and Environment 8(3-4): 204-222
[33] Begun J W, Zimmerman B and Dooley K 2003 Health care organizations as complex adaptive systems. Advances in health care organization theory, pp. 253, 288

[34] Morrow D and Rondinelli D 2002 Adopting corporate environmental management systems: motivations and results of ISO 14001 and EMAS certification. European Management Journal 20(2): 159-171

[35] Judge W Q and Ryman J A 2001 The shared leadership challenge in strategic alliances: lessons from the US healthcare industry. The Academy of Management Executive 15(2): 71-79

[36] Lundgren R E and McMakin A H 2018 Risk communication: a handbook for communicating environmental, safety, and health risks. John Wiley \& Sons

[37] Reynolds B and Seeger M W 2005 Crisis and emergency risk communication as an integrative model. Journal of Health Communication 10(1): 43-55

[38] Wisner B and Adams J (Eds.) 2002 Environmental health in emergencies and disasters: a practical guide. Geneva: World Health Organization

[39] Kawakami T, Kogi K, Toyama N and Yoshikawa T 2004 Participatory approaches to improving safety and health under trade union initiative. Industrial Health 42(2): 196-206

[40] Zadeh L A 1965 Information and control. Fuzzy Sets 8(3): 338-353

[41] Luthra S, Govindan K, Kharb R K and Mangla S K 2016 Evaluating the enablers in solar power developments in the current scenario using fuzzy DEMATEL: an Indian perspective. Renewable and Sustainable Energy Reviews 63: 379-397

[42] Altuntas S, Selim, H and Dereli T 2014 A fuzzy DEMATELbased solution approach for facility layout problem: a case study. The International Journal of Advanced Manufacturing Technology 73(5-8): 749-771

[43] Patil S K and Kant R 2014 A fuzzy AHP-TOPSIS framework for ranking the solutions of Knowledge Management adoption in Supply Chain to overcome its barriers. Expert Systems with Applications 41(2): 679-693

[44] Sangaiah A K, Gopal J, Basu A and Subramaniam P R 2017 An integrated fuzzy DEMATEL, TOPSIS, and ELECTRE approach for evaluating knowledge transfer effectiveness with reference to GSD project outcome. Neural Computing and Applications 28(1): 111-123

[45] Govindan K, Kannan D and Shankar K M 2014 Evaluating the drivers of corporate social responsibility in the mining industry with multi-criteria approach: a multi-stakeholder perspective. Journal of Cleaner Production 84: 214-232

[46] Chang B, Chang C W and Wu C H 2011 Fuzzy DEMATEL method for developing supplier selection criteria. Expert Systems with Applications 38(3): 1850-1858

[47] Zhou Q, Huang W and Zhang, Y. 2011 Identifying critical success factors in emergency management using a fuzzy DEMATEL method. Safety Science 49(2): 243-252

[48] BaykasoğLu A, KaplanoğLu V, Durmuş ŎgLu Z D and Şahin C 2013 Integrating fuzzy DEMATEL and fuzzy hierarchical TOPSIS methods for truck selection. Expert Systems with Applications 40(3): 899-907

[49] Lin R J 2013 Using fuzzy DEMATEL to evaluate the green supply chain management practices. Journal of Cleaner Production 40: 32-39 
[50] Tseng M L and Lin Y H 2009 Application of fuzzy DEMATEL to develop a cause and effect model of municipal solid waste management in Metro Manila. Environmental Monitoring and Assessment 158(1-4): 519

[51] Tadić S, Zečević S and Krstić M 2014 A novel hybrid MCDM model based on fuzzy DEMATEL, fuzzy ANP and fuzzy VIKOR for city logistics concept selection. Expert Systems with Applications 41(18): 8112-8128

[52] Govindan K, Khodaverdi R and Vafadarnikjoo A 2015 Intuitionistic fuzzy based DEMATEL method for developing green practices and performances in a green supply chain. Expert Systems with Applications 42(20): 7207-7220 